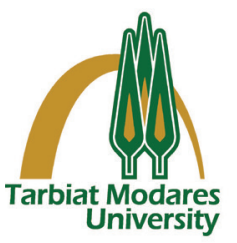

\title{
In-Vitro Antifungal Activity of Nano Encapsulated Caprylic Acid and EFG1 Gene Expression Profile in Candida albicans
}

\section{A R T I C L E I N F O}

Article Type

Original Research

Authors

Reyhaneh Zarimeidani, $M S c^{1}$ Shahla RoudbarMohammadi, $P h D^{1^{*}}$ Maryam Roudbary, $P h D^{2}$ Fatemeh Nikoomanesh, $P h D^{3}$ Peyman Aslani, $P h D^{4}$ Sanaz Yaalimadad, $M S c^{1}$

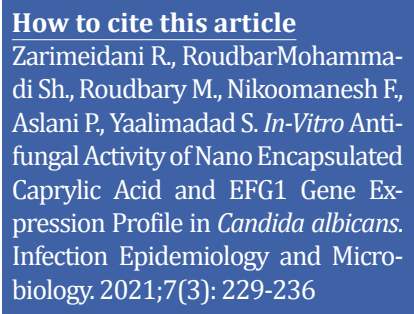

${ }^{1}$ Department of Mycology, Faculty of Medical Science, Tarbiat Modares University, Tehran, Iran ${ }^{2}$ Department of Parasitology and Mycology, School of Medicine, Iran University of Medical Sciences, Tehran, Iran

${ }^{3}$ Infectious Diseases Research Center Birjand University of Medical Sciences, Birjand, Iran

${ }^{4}$ Department of Parasitology and Mycology, Faculty of Medicine, Aja University of Medical Sciences

\section{* Correspondence}

Address: Department of Medical Mycology, Faculty of Medical Sciences, Tarbiat Modares University, Sh.Mohammadi@modares.ac.ir

\section{A B S T R A C T}

Backgrounds: Due to the emergence of multidrug-resistant Candida species, the discovery of new antifungal agents with minimum side effects is essential. The aim of this study was to investigate the antifungal activity of caprylic acid and nano-encapsulated caprylic acid against $C$. albicans as well as their effect on the expression of EFG1 gene.

Materials \& Methods: In this laboratory trial study, the minimum inhibitory concentration (MIC) of caprylic acid and nano-encapsulated caprylic acid against $C$. albicans was evaluated at various concentrations (400-625 and 1.3-50 $\mu \mathrm{L} / \mathrm{mL}$, respectively). Real time-PCR was performed to assess the expression level of EFG1 gene. Cytotoxicity effect of caprylic acid and nano-encapsulated caprylic acid was evaluated on SW480 cell line using MTT test.

Findings: Antifungal activity findings displayed that $\mathrm{MIC}_{90}$ and $\mathrm{MIC}_{50}$ values of caprylic acid were 500 and $450 \mu \mathrm{g} / \mathrm{mL}$, respectively, whereas MIC $_{90}$ and MIC $_{50}$ values of nano-encapsulated caprylic acid were 6.2 and $3.1 \mu \mathrm{g} / \mathrm{mL}$, respectively. The expression of EFG1 gene significantly decreased in the groups treated with caprylic acid and nano-encapsulated caprylic acid compared to the control group. According to the cytotoxicity evaluation findings, the viability of cells treated with caprylic acid was significantly higher than that of cells exposed to nanoencapsulated caprylic acid.

Conclusions: According to the obtained results, nano-encapsulated caprylic acid successfully inhibited C. albicans growth at a lower concentration compared to caprylic acid. Overall, it was found that nano-encapsulated caprylic acid is a promising antifungal agent against Candida species; however, further studies are needed to be performed about nano-encapsulation of caprylic acid.

Keywords: Candida albicans, Caprylic acid, Nano-encapsulation, EFG1 gene, Antifungal agent CITATION LINKS

[1] Khan MSA, Ahmad I, Aqil F, Owais M, Shahid M, Musarrat J. Virulence and ... [2] Cleveland AA, Harrison LH, Farley MM, Hollick R, Stein B, Chiller TM, et al. Declining ... [3] Klingspor L, Tortorano AM, Peman J, Willinger B, Hamal P, Sendid B, et al. Invasive Candida ... [4] Finkel JS, Mitchell AP. Genetic control of Candida albicans ... [5] Stanley NR, Lazazzera BA. Environmental signals and ... [6] Ganguly S, Mitchell A. Mucosal biofilm of ... [7] Donlan RM, Costerton JW. Biofilms: Survival mechanisms of ... [8] Srikantha T, Tsai LK, Daniels K, Soll DR. EFG1 ... [9] Sohn K, Urban C, Brunner H, Rupp S. EFG1 is a major ... [10] Nadeem SG, Shafiq A, Hakim ST, Anjum Y, Kazm SU. Effect of growth ... [11] Guinea J, Sánchez-Somolinos M, Cuevas O, Peláez T, Bouza E. Fluconazole resistance ... [12] Nuzhat T, Vidyasagar GM. Antifungal investigations on plant ... [13] Walters D, Raynor L, Mitchell A, Walker R, Walker K. Antifungal ... [14] Thibane VS, Kock JL, Ells R, Van Wyk PW, Pohl CH. Effect of ... [15] Murzyn A, Krasowska A, Stefanowicz P, Dziadkowiec D, Łukaszewicz M. Capric acid ... [16] Carballeira N. New advances in fatty acids as antimalarial, antimycobacterial, and ... [17] Traul KA, Driedger A, Ingle DL, Nakhasi D. Review of the toxicologic ... [18] Kumari A, Yadav SK, Yadav SC. Biodegradable polymeric ... [19] Nahar M, Dutta T, Murugesan S, Asthana A, Mishra D, Rajkumar V, et al. Functional polymeric ... [20] Nikoomanesh F, Roudbar Mohammadi S, Khoobi M, Haghighi F, Roudbary M. Design and ... [21] Nikoomanesh F, Bashardoust B. Effect of farnesol on responsive gene ... [22] Roudbary M, Roudbar Mohammadi S, Bakhshi B, Farhadi Z, Nikoomanesh F. Identification of ... [23] Trewyn BG, Slowing II, Giri S, Chen H-T, Lin VS-Y. Synthesis and functionalization of ... [24] Chinatangkul N, Limmatvapirat C, Nunthanid J, Luangtana-Anan M, Sriamornsak P, Limmatvapirat S. Design and ... [25] Zhang H, Zhai Y, Wang J, Zhai G. New progress and prospects: The application of nanogel in drug delivery. Mater Sci Eng C. 2016;60:560-8. [26] Avis TJ, Bélanger RR. Specificity and mode of action of the ... [27] Bergsson G, Arnfinnsson J, Steingrímsson Ó, Thormar H. In vitro ... [28] Takahashi M, Inoue S, Hayama K, Ninomiya K, Abe S. Inhibition of .. [29] Carvalho FC, Bruschi ML, Evangelista RC, Daflon Gremiao MP. Mucoadhesive drug ... [30] Srikantha T, Tsai LK, Daniels K, Soll DR. EFG1 null mutants of Candida ... 


\section{Introduction}

Candida albicans is a polymorphic fungus which causes as opportunistic fungal infection in immunocompromised patients [1]. Candida infections are mainly caused by the organism's ability to form biofilm on living and non-living surfaces, respectively. According to some reports from the United States, the mortality rate due to Candida infections associated to the use of medical equipment is estimated to be as high as $30 \%$, which imposes high cost to the community for antifungal therapies. Today, biofilm formation is known as the main cause of pathogenesis of $C$. albicans. While this phenomenon could turn into a systemic infection, it is characterized by drug resistance [2-5].

Biofilm formation starts from changes in phenotypic cells, distinct from planktonic cells, to hyphal formation and in mature biofilm, extracellular matrix surrounds all materials ${ }^{[6-7]}$. Genetic analysis has revealed that network genes navigate biofilm formation. One of the major regulators of biofilm formation in C. albicans is enhanced filamentous growth protein I (EFG1) ${ }^{[8]}$. On the other hand, EFG1 as a transcription factor has several target genes that regulate the expression of hyphal genes including HWP1, HYR1, and ALS3 [8-10]. Understanding the gene expression patterns in Candida biofilm is of great interest to investigators in order to identify potential antifungal targets. Application of conventional antifungal drugs has been limited due to toxicity, side effects, and the development of multidrug-resistant Candida species [11-13]. Recently, the use of natural-based compounds has attracted much attention because of their antifungal characteristics. Previous studies have shown that fatty acids are effective against pathogenic fungi in plants and human ${ }^{[14]}$. Caprylic acid found in coconut is one of the triglycerides family members, including caprylic acid (CAP, C8), capric (C10), caproic (C6), and lauric (C12) fatty acids. A previous study reported that medium-chain fatty acids had potent antibacterial, antifungal, and anti-inflammatory properties ${ }^{[15]}$. Therefore, these properties make caprylic acid as a useful treatment for fungal infections. In addition, unlike surfactants and synthetic peptides, fatty acids have shown no toxicity, hypersensitivity, carcinogenicity, and mutagenic effects on mammalian cells so far [16-17].

Objectives: Nowadays, the design of drug delivery nano systems, such as liposomes, micelles, nanoparticles, antibody conjugates, and polymer conjugate systems, has attracted much attentions. This novel approach represents a significant improvement in pharmaceutical systems due to enhanced targeted and controlled drug delivery with low dose and slow rate to tissues or cells ${ }^{[18-20]}$. This study aimed to investigate the activity of caprylic acid and nano-encapsulated caprylic acid against $C$. albicans biofilm formation and to evaluate the effect of these compounds on the expression of EFG1 gene as a transcription factor of biofilm formation in C. albicans.

\section{Materials \& Methods}

This laboratory trial study was carried out at Tarbiat Modares University, Tehran, Iran. In this study, antifungal activity evaluation was done on C. albicans (ATCC 10231). The strain was cultured on Sabouraud dextrose agar (Merck, Germany) medium and incubated at $37{ }^{\circ} \mathrm{C}$ for $24 \mathrm{hrs}$. Caprylic acid and encapsulated caprylic acid were purchased from Nano Zino Company, Iran. Caprylic acid (Sigma Aldrich, USA) was prepared at different concentrations in methanol $(650,625,600,550$, and $500 \mathrm{mg} /$ $\mathrm{mL}$ ). Nano-encapsulated caprylic acid was also prepared at $50,25,12.5,6.25,3.1$, and $1.5 \mathrm{mg} / \mathrm{mL}$ concentrations. 
Effect of caprylic acid and nanoencapsulated caprylic acid on biofilm formation: The inhibitory activity of caprylic acid and nano-encapsulated caprylic acid against $C$. albicans biofilm formation was evaluated according to a previous study by Nikoomanesh et al. (2018) ${ }^{[21]}$. Briefly, for biofilm formation assay, fungal cells $\left(10^{3}\right.$ cell/ $\mathrm{mL}$ ) were inoculated in 96-well microplates (Nunc), while each well contained $200 \mu \mathrm{L}$ of RPMI (Sigma-Aldrich, USA) medium supplemented with different concentrations of caprylic acid $(650,625,600,550$, and 500 $\mathrm{mg} / \mathrm{mL}$ ) and nano-encapsulated caprylic acid ( 50, 25, 12.5, 6.25, 3.1, and $1.5 \mathrm{mg} / \mathrm{mL})$. Positive control contained fluconazole, and suspensions with no fungal elements were considered as negative control during tests. The plates were incubated at $35^{\circ} \mathrm{C}$ for $24 \mathrm{hrs}$. Minimum inhibitory concentration (MIC) was determined with the aid of a magnifying mirror. The lowest drug concentration causing a prominent decrease in turbidity (minimum inhibitory concentration that could inhibit $50 \%$ of fungal cells growth) was regarded as $\mathrm{MIC}_{50}$, and the growth rate in each well was compared to that of the positive control. Moreover, $\mathrm{MIC}_{90}$ (the MIC which could inhibit $90 \%$ of fungal cells growth) was detected. Then to determine the minimum fungicidal concentration (MFC), each well was cultured on SDA and incubated at $37{ }^{\circ} \mathrm{C}$ for $24 \mathrm{hrs}$, and colony count was performed. All experiments were carried out in triplicate.

Real-time PCR (qRT-PCR): To investigate the effect of caprylic acid on gene expression, real-time PCR was performed.

RNA extraction: After obtaining MIC, fresh culture colonies of $C$. albicans at $10^{3}$ cells/ $\mathrm{mL}$ were prepared and treated with the MIC of caprylic acid and nano-encapsulated caprylic acid at $37{ }^{\circ} \mathrm{C}$ for $24 \mathrm{hrs}$. Wells without caprylic acid/nano-encapsulated caprylic acid were considered as positive control, and itraconazole-containing wells were considered as negative control. After that the treated fungal cells were collected and washed using phosphate buffered saline (PBS), and total mRNA was extracted by glass bead and lysis buffer as described previously [20].

cDNA synthesized; cDNA was synthesized according to the manufacturer's recommendations using a 2-step cDNA synthesis kit, vivantis (Malassezia) ${ }^{\text {[22]. The }}$ PCR primers used to amplify and identify EFG1 gene were designed by All-ID design software, and the housekeeping gene Act1 was used as an internal control. The primer sequences used in this study are shown in Table 1.

Real-time PCR was accomplished using AMPLIQON (Real Q plus 2 x master mixes Green High Rox) [20]. The reaction mixture, adjusted to a final volume of $20 \mu \mathrm{L}$ using DEPC water, contained $10 \mu \mathrm{L}$ of master mix (Green High Rox), $0.5 \mu \mathrm{L}$ of each specific primer of EFG1 (10 pmol), and $2 \mu \mathrm{L}$ of each cDNA sample. Cycling conditions were as follows: an initial denaturation step at $94{ }^{\circ} \mathrm{C}$ for $2 \mathrm{~min}$, followed by 40 cycles of denaturation at $94{ }^{\circ} \mathrm{C}$ for 30 s., $58{ }^{\circ} \mathrm{C}$ for $30 \mathrm{~s}$, and $72{ }^{\circ} \mathrm{C}$ for $30 \mathrm{~s}$.

All reactions were performed in triplicate in the ABI one step (Applied Biosystems; Rotkreuz; Switzerland). The expression level of EFG1 was evaluated using REST 2009 software Ver. 2.0.13.

Cytotoxicity Assay: The cytotoxicity effect of caprylic acid and nano-encapsulated caprylic acid was assessed by colorimetric MTT assay ${ }^{[20]}$. In this method, epithelial cell line (SW480) was cultured in DMEM cell culture medium supplemented with $10 \%$ fetal bovin serum (FBS), $50 \mu \mathrm{L}$ penicillin/ streptomycin, and l-glutamine and incubated at $37{ }^{\circ} \mathrm{C}$ for $24 \mathrm{hrs}$ with $5 \% \mathrm{CO}_{2}$. Then cells at $10 \times 1^{4}$ cells $/ \mathrm{mL}$ were seeded into each well of microtiter plates (tissue culture grade, 96 wells, flat bottom, Corning. USA), containing 
determined concentrations of caprylic acid and nano-encapsulated caprylic acid. Also, non-treated cells were considered as the control group. Viability of cells was tested by MTT ( $5 \mathrm{mg} / \mathrm{mL}$, Sigma-Aldrich, USA) at $570 \mathrm{~nm}$ using an ELISA reader. Cell viability percentage was calculated and compared to the control group. Cell viability was calculated by the following formula:

Cell viability $=$ ODTest $/$ ODcontrol $\times 100$

Statistical Analysis: Data were analyzed using IBM SPSS statistics software Version 23 by employing student-test and one-way ANOVA. A $p$ value $<.05$ was considered as a significant difference between groups.

\section{Findings}

Activity of caprylic acid and nano encapsulated caprylic acid on biofilm formation: Antifungal activity of caprylic acid and nano-encapsulated caprylic acid was examined against biofilm formation ability of $C$. albicans. The findings indicated that $C$. albicans in the presence of caprylic acid and nano-encapsulated caprylic acid at 550 and $6.25 \mu \mathrm{g} / \mathrm{mL}$ concentrations showed the least growth, respectively. Moreover, caprylic acid and nano encapsulated caprylic acid at 450 and $3.1 \mu \mathrm{g} / \mathrm{mL}$ concentrations were able to inhibit the growth of this organism. (Table 2).

EFG1 gene expression: RNA was extracted from C. albicans before and after treatment with MIC values of caprylic acid and nanoencapsulated caprylic acid. The effect of caprylic acid and nano-encapsulated caprylic acid on the expression of EFG1 gene was evaluated, and the results showed a significant decrease in the expression of EFG1 gene in C. albicnas treated with nano-encapsulated caprylic acid compared to the caprylic acid-treated and control groups. Gene expression analysis showed that treatment of $C$. albicans with caprylic acid and nano-encapsulated caprylic acid significantly decreased EFG1 gene expression compared to the non-treated group $(p<.01)$ (Figure 1$)$.

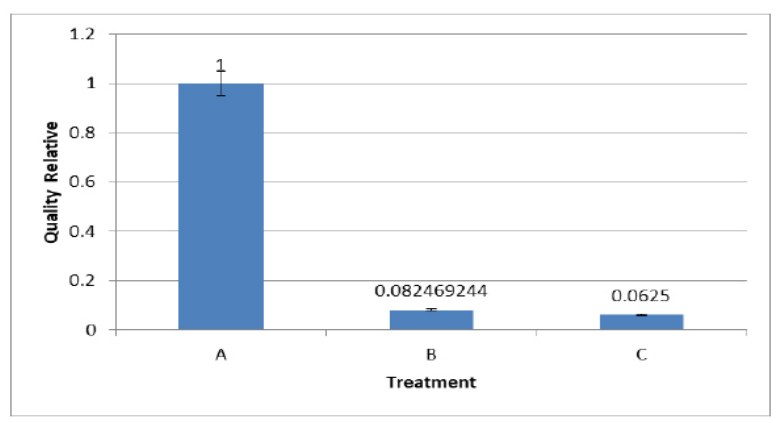

Figure 1) C. albicans EFG1 gene expression before and after treatment with MIC values of caprylic acid and nano-encapsulated caprylic acid. Act1 was used as internal control. A: non-treated sample; B: caprylic acid treated group; C: nano-encapsulated caprylic acid treated group.

Cytotoxicity Assay: The cytotoxicity effect of caprylic acid and nano-encapsulated caprylic acid was examined on SW480 cell line using MTT test. Cells treated with caprylic acid at $450 \mu \mathrm{g} / \mathrm{mL}$ concentration showed higher viability compared to those treated with nano-encapsulated caprylic acid at $3.1 \mu \mathrm{g} /$ $\mathrm{mL}$, and this difference was significant $(p$ value $=.15$, Figure 2 ). The results showed that cells treated with caprylic acid represented higher viability than those treated with nano encapsulated caprylic acid.

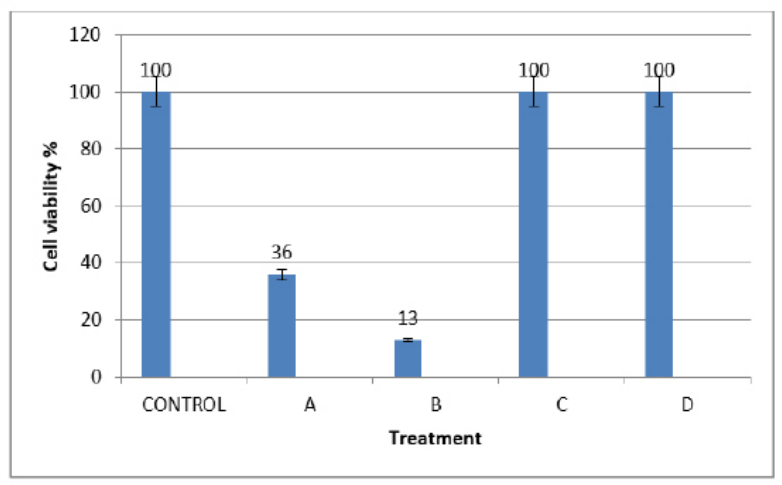

Figure 2) Comparison of the viability of SW480 cell line treated with different concentrations of caprylic acid. A: nano-encapsulated caprylic acid at $3.1 \mu \mathrm{g} / \mathrm{mL}$, B: nanoencapsulated caprylic acid at $6.2 \mu \mathrm{g} / \mathrm{mL}$, C: caprylic acid at $500 \mu \mathrm{g} / \mathrm{mL}$, D: caprylic acid at $450 \mu \mathrm{g} / \mathrm{mL}$ 
Table 1) Primer sequences used in this study for real-time PCR assay

\begin{tabular}{lll}
\hline Primer Name & Sequence (5' to $\mathbf{3}^{\prime}$ ) & PCR Product Size(bp) \\
\hline EFG1-F & TATGCCCCAGCAAACTG & 140 \\
EFG1-R & TTGTTGTCCTGCTGTCTGTC & 110 \\
\hline ACT1-F & TGCCTCTGGTCGTACCACTG \\
ACT1-R & GCGAAACCTTCGTAGATGGG & 110 \\
\hline
\end{tabular}

Table 2) The MIC and MFC values of caprylic acid and nano-encapsulated caprylic acid against $C$. albicans.

\begin{tabular}{llll}
\hline Substance & MFC $(\mu \mathrm{g} / \mathrm{mL})$ & MIC $_{90}(\mu \mathrm{g} / \mathrm{mL})$ & MIC $_{50}(\mu \mathrm{g} / \mathrm{mL})$ \\
\hline Caprylic acid & 600 & 550 & 450 \\
\hline Nanocapsulated caprylic acid & 12.5 & 6.25 & 3.1 \\
\hline
\end{tabular}

\section{Discussion}

In the present study, the antifungal activity of caprylic acid and nano-encapsulated caprylic acid as well as their effects on the expression of EFG1 gene of $C$. albicans were investigated. The obtained results showed that caprylic acid at $\mathrm{MIC}_{50}$ value exhibited antifungal effect on C. albicans (ATCC10231). Also, nano-encapsulated caprylic acid at identified concentration inhibited the growth of $C$. albicans and the expression of EFG1 gene. These findings demonstrated that both nano-encapsulated caprylic acid and caprylic acid were effective against $C$. albicans biofilm formation.

Candidiasis still remains as one of the most important opportunistic fungal infections in immunocompromised patients worldwide [1]. Multidrug resistance in Candida strains against common antifungal agents has been reported to be increasing. However, the existing antifungal agents are widely used in the treatment of fungal infection ${ }^{3-}$ ${ }^{6}$. Nowadays, the use of new drug delivery strategies to deliver antifungal agents in the treatment of fungal infections has received much attention. Therefore, the effectiveness of natural-based antifungal agents would be increased by employing new drug delivery systems, such as nano-encapsulated system [23-25].
Fatty acids penetrate the cell membrane of fungi, thereby leading to the disruption of cell membrane integrity ${ }^{[15]}$. Previous studies have confirmed the antimicrobial effect of fatty acids; in a study conducted by Avis et al. (2001), medium-chain fatty acids were shown to induce membrane dysfunction and cell death ${ }^{[26]}$. Similarly, Bergson et al. (2001) indicated caprylic acid antifungal properties [27]. Takahashi et al. (2012) showed caprylic acid inhibitory activity against $C$. albicans growth and its effectiveness in the treatment of oral candidiasis in rats ${ }^{[28]}$. Therefore, in this study for the first time, nano-encapsulated caprylic acid was designed and synthesized to investigate its antifungal properties.

These findings revealed that the use of nanostructure caused caprylic acid to inhibit Candida growth at a lower concentration than caprylic acid without a nanostructure; in addition, nano-encapsulation improved the antifungal activity of caprylic acid. Therefore, the design of drug delivery systems based on nano compounds has several advantages as follows: overcoming defects in pharmaceutical formulation, increasing drug retention time at the desired site, decreasing drug administration time, and uniform drug distribution ${ }^{[29]}$. On the other hand, according to the cytotoxicity examination results, caprylic acid at $\mathrm{MIC}_{50}$ 
value showed the lowest cytotoxicity effect against SW480 cell line; however, at higher concentrations the viability of cells decreased; therefore, it acted in a dosedependent manner.

Interestingly, the viability of cells in the presence of nano-encapsulated caprylic acid decreased compared to caprylic acid. In a previous study conducted by Carballeira et al, (2008), caprylic acid at different concentrations showed no cytotoxicity effect on the epithelium cell line ${ }^{[16]}$. As a result, the form of nanocapsulation probably has a toxic effect on the cell line. In this regard, the silica used in the structure of nanocapsule in combination with caprylic acid is likely to induce a toxic effect.

According to the obtained findings, nanoencapsulated caprylic acid significantly down regulated $C$. albicans EFG1 gene expression. It is well-known that EFG1 gene is a major transcription factor responsible for pathogenesis as well as transformation of yeast to hyphae; adhesion and hyphae formation are the most important virulence factors of C. albicans ${ }^{[30]}$.

A previous study explained that in mutant strains of $C$. albicans, the pathogenicity and tissue invasion significantly diminished through defects in EFG1 gene expression. Overall, it seems that the design of drug delivery systems based on nanostructure increases the efficacy of drugs while reducing their dose. Also, it could reduce the pathogenicity of $C$. albicans by inhibiting the related genes involved in the progression of Candida infections. In any case, in addition to the drug efficacy and drug delivery system, it is necessary to pay attention to the side effects of the strategy used, including nanocarriers, which are interestingly investigated today.

\section{Conclusion}

The present study showed that caprylic acid and nano-encapsulated caprylic acid might be mentioned as efficient agents against candidiasis. Hence, it is suggested that more comprehensive studies be conducted on other natural antifungal agents and drug delivery strategies that have antifungal properties to fight against fungal infections.

Acknowledgements: This study was carried out in collaboration with the staff of Department of Medical Mycology in Faculty of Medical Sciences in Tarbiat Modares University in Tehran, IR Iran, they are appreciated for their collaboration.

Ethical Permissions: This study was approved by Ethics Committee of Tarbiat Modares University, Teharn, Iran (IR.TUM. REC.1394.207).

Conflicts of Interests: The author declares no conflict of interests.

Authors' Contribution: Conceptualization: RZ; Data curation and formal analysis: RZ, FN; Investigation: RZ; Methodology and project administration: SHR; Supervision: SHR; Validation: MR; Writing of original draft: RZ; Writing, reviewing, and editing: FN,PA,SY. Fundings: This study was supported by Tarbiat Modares University in Tehran, Iran (Grant No. Med5824).

Consent to participate: Not Applicable.

\section{Reference}

1. Khan MSA, Ahmad I, Aqil F, Owais M, Shahid M, Musarrat J. Virulence and pathogenicity of fungal pathogens with special reference to Candida albicans. In Combating fungal infections. Berlin, Heidelberg: Springer; 2010, pp. 21-45.

2. Cleveland AA, Harrison LH, Farley MM, Hollick R, Stein B, Chiller TM, et al. Declining incidence of candidemia and the shifting epidemiology of Candida resistance in two US metropolitan areas. PLoS One. 2015;10(3):e0120452.

3. Klingspor L, Tortorano AM, Peman J, 
Willinger B, Hamal P, Sendid B, et al. Invasive Candida infections in surgical patients inintensive care units: A prospective multicentre survey initiated by the European Confederation of Medical Mycology (ECMM)(2006-2008). Clin Microbiol Infect. 2015;21(1):87-e1.

4. Finkel JS, Mitchell AP. Genetic control of Candida albicans biofilm development. Nat Rev Microbiol. 2011;9(2):109-18.

5. Stanley NR, Lazazzera BA. Environmental signals and regulatory pathways that influence biofilm formation. Mol Microbiol. 2004;52(4):917-24.

6. Ganguly S, Mitchell A. Mucosal biofilm of Candida albicans. Curr Opin Microbiol. 2011;14(4):380-5.

7. Donlan RM, Costerton JW. Biofilms: Survival mechanisms of clinically relevant microorganisms. Clin Microbiol Rev. 2002;15(2):167-93.

8. Srikantha T, Tsai LK, Daniels K, Soll DR. EFG1 null mutants of Candida albicans switch but cannot express the complete phenotype of white-phase budding cells. J Bacteriol. 2000;182(6):1580-91.

9. Sohn K, Urban C, Brunner H, Rupp S. EFG1 is a major regulator of cell wall dynamics in Candida albicans as revealed by DNA microarrays. Mol Microbiol. 2003;47(1):89-102.

10. Nadeem SG, Shafiq A, Hakim ST, Anjum Y, Kazm SU. Effect of growth media, $\mathrm{pH}$, and temperature on yeast to hyphal transition in Candida albicans. Open J Med Microbiol. 2013;3(3):185-92.

11. Guinea J, Sánchez-Somolinos M, Cuevas O, Peláez T, Bouza E. Fluconazole resistance mechanismsin Candida krusei: The contribution of efflux-pumps. Med Mycol. 2006;44(6):575-8.

12. Nuzhat T, Vidyasagar GM. Antifungal investigations on plant essential oils. Int J Pharm Pharmaceut Sci. 2013;5(Suppl 2):19-28.
13. Walters D, Raynor L, Mitchell A, Walker $\mathrm{R}$, Walker K. Antifungal activities of four fatty acids against plant pathogenic fungi. Mycopathologia. 2004;157(1):8790.

14. Thibane VS, Kock JL, Ells R, Van Wyk PW, PohlCH.Effect of marine polyunsaturated fattyacids on biofilm formation of Candida albicans and Candida dubliniensis. Mar Drugs. 2010;8(10):2597-604.

15. Murzyn A, Krasowska A, Stefanowicz P, Dziadkowiec D, Łukaszewicz M. Capric acid secreted by $S$. boulardii inhibits Candida albicans filamentous growth, adhesion, and biofilm formation. PLoS One. 2010;5(8):e12050.

16. Carballeira N. New advances in fatty acids as antimalarial, antimycobacterial, and antifungal agents. Prog Lipid Res. 2008;47(1):50-61.

17. Traul KA, Driedger A, Ingle DL, Nakhasi D. Review of the toxicologic properties of medium-chain triglycerides. Food Chem Toxicol. 2000; 38(1);79-98.

18. Kumari A, Yadav SK, Yadav SC. Biodegradable polymeric nanoparticles based drug delivery systems. Colloids Surf B Biointerfaces. 2010;75(1):1-18. 19. Nahar M, Dutta T, Murugesan S, Asthana A, Mishra D, Rajkumar V, et al. Functional polymeric nanoparticles: An efficient and promising tool for active delivery of bioactives. Crit Rev Ther Drug Carrier Syst. 2006;23(4):259-318.

20. Nikoomanesh F, Roudbar Mohammadi S, Khoobi M, Haghighi F, Roudbary M. Design and synthesis of mucoadhesive nanogel containing farnesol: Investigation of the effect on HWP1, SAP6, and Rim101 genes expression of Candida albicans in vitro. Artif Cells Nanomed Biotechnol. 2019;47(1):64-72.

21. Nikoomanesh F, Bashardoust B. Effect of farnesol on responsive gene expressions in hyphal morphogenesis transformation 
of Candida albicans. Infect Epidemiol Microbiol. 2018;4(2):73-7.

22. Roudbary M, Roudbar Mohammadi S, Bakhshi B, Farhadi Z, Nikoomanesh F. Identification of Candida species isolated form Iranian women eith vaginal candidasis by PCR-RFLP method. Eur J Exp Biology. 2013;3(6):365-9.

23. Trewyn BG, Slowing II, Giri S, Chen H-T, Lin VS-Y. Synthesis and functionalization of a mesoporous silica nanoparticle based on the sol-gel process and applications in controlled release. Acc Chem Res. 2007;40(9):846-53.

24. Chinatangkul N, LimmatvapiratC, Nunthanid J, Luangtana-Anan M, Sriamornsak P, LimmatvapiratS. Designand characterization of monolaurin loaded electrospun shellac nanofibers with antimicrobial activity. Asian J Pharm Sci. 2018;13(5):459-71.

25. Zhang H, Zhai Y, Wang J, Zhai G. New progress and prospects: The application of nanogel in drug delivery. Mater Sci Eng C. 2016;60:560-8.

26. Avis TJ, Bélanger RR. Specificity and mode of action of the antifungal fatty acid cis-9-heptadecenoic acid produced by Pseudozyma flocculosa. Appl Environ Microbiol. 2001;67(2):956-60.

27. Bergsson G, Arnfinnsson J, Steingrímsson Ó, Thormar H. In vitro killing of Candida albicans by fatty acids and monoglycerides. Antimicrob Agents Chemother. 2001;45(11):3209-12.

28. Takahashi M, Inoue S, HayamaK, Ninomiya $\mathrm{K}$, Abe S. Inhibition of Candida mycelia growth by a medium chain fatty acids, capric acid in vitoro and its therapeutic efficacy in murine oral candidiasis. Med Mycol J. 2012;53(4):255-61.

29. Carvalho FC, Bruschi ML, Evangelista RC, Daflon Gremiao MP. Mucoadhesive drug delivery systems. Braz J Pharm Sci. 2010;46(1):1-17.

30. Srikantha T, Tsai LK, Daniels K, Soll DR. EFG1 null mutants of Candida albicans switch but cannot express the complete phenotype of white-phase budding cells. J Bacteriol. 2000;182(6):1580-91. 